\title{
Assessing The Organizational Readiness For IMPLEMENTING BI SYSTEMS
}

\author{
Aylin Hejazi ${ }^{1}$, Neda Abdolvand ${ }^{2}$, Saeedeh Rajaee Harandi ${ }^{3}$ \\ ${ }^{1}$ Department of Social Science and Economics, Alzahra University, Tehran, Iran \\ ${ }^{2}$ Assistant Professor, Department of Social Science and Economics, Alzahra University, \\ Tehran, Iran \\ ${ }^{3}$ Department of Social Science and Economics, Alzahra University, Tehran, Iran
}

\begin{abstract}
Implementation of business intelligence systems $(B I S)$ is very complex and requires a lot of resources and time. Business intelligence (BI) is a difficult concept and has a multi-tier architecture. The metadata causes the complexity of the BI. That is why a BI readiness model is required. The frequency of BI maturity models, such as the data warehousing (TDW), has been provided, but there are few frameworks for measuring the readiness. Moreover, readiness frameworks often provide a general model for all organizations. Hence, the objective of this study was to examine whether the factors affecting the organizational readiness for BI implementation in all organizations are identical. For this purpose, based on a comprehensive literature review, four factors of culture, people, strategy, and management were extracted as the most important factors affecting the readiness and implementation of BI, and they were studied in three educational, commerce, and IT organizations. Based on the findings, different factors affect various organizations, and using a general model should not be advised.
\end{abstract}

\section{KEYWORDS}

Organizational readiness, Business Intelligence, BI system, BI Implementation.

\section{INTRODUCTION}

Since Howard Dresner introduced the concept of business intelligence (BI), the area of information systems (IS) has encountered the rapid development of systems and applications to support decisions (Buchanan \& O Connell, 2006). According to the findings, implementation and appropriate application of BI can lead to benefits, such as improved profitability and efficiency as well as reduced costs. Although many organizations have implemented BI for its benefits, many of these efforts have not been successful [17]. According to Howson, only $24 \%$ of BI projects have been successful [15]. Researchers and business owners have studied the return on investment (ROI) of BI projects [1] [29], the readiness of organizations for implementing BI systems [1] [2], and the factors affecting BI success [17]. According to the studies, the cost of BI implementation will vary from fifty-thousand to millions of dollars for implementing the complicated warehouse projects, and it is possible that billions of dollars [1] be spent to accomplish this goal [23] [31], without success or achieving any positive effects.

On the BI and ROI subjects, the development methods based on business and reengineering business processes have been studied to ensure the ROI of BI. As part of this approach, the BI readiness assessment was used to determine the degree of organizational readiness to implement DOI:10.5121/ijitcs.2016.6102 
BI and to achieve all BI values [29]. Eckerson, Williams and Williams, Anjariny \& Zeki, and Anjariny et al. have studied the factors affecting the readiness to implement BI [9] [29] [1] [2]. However, there is no complete description of how to get ready for successful BI implementation. Williams and Williams believed that readiness for BI depends on the readiness for implementing a data warehouse and assessing its characteristics. On the other hand, other changes, such as changing process to take advantage of all $\mathrm{BI}$ values and ROI assurance, are essential [30]. If the readiness for software and hardware implementation of $\mathrm{BI}$ is considered as the hardest aspect, the readiness for processes and organizational management could be considered as the soft aspect. While the hard aspects are under the influence of IT assets, including information systems (IS) and technical knowledge of employees and consultants, the soft aspects are affected by organizational culture. Studies focused on IT and culture indicated the different results of different models in various organizations. For example, El-Mekawy et al. study of the strategic alignment on two organizational branches in two different countries indicated the different results [11]. Leidner believed that culture affects the individual and organizational behavior, and causes different results of IT systems such as BI systems [20].

This study focused on the subject that how culture and different IT assets affect the effective factors on the organizational readiness for BI implementation. Hence, first by a comprehensive study of literature, factors affecting the readiness for BI implementation were extracted and a conceptual model was developed. Then, the model was tested in three different educational, commercial and IT organizations to determine whether the factors affecting the organizational readiness in all organizations are identical. The results of this study could help organizations to select and develop the models of BI readiness assessment. The study followed by the review of the research methodology. The last part of the research includes the conclusion and recommendation of the study.

\section{LITERATURE REVIEW}

\subsection{Organizational Readiness for BI Implementation}

Readiness for BI could be considered as the risk analysis of BI system's implementation, which aims to increase the potential ROI [30]. Readiness Assessment is necessary for two reasons. First Readiness Assessment is a key tool for BI risk analysis [15] that extracts the gaps [30]. The gap refers to the areas where, despite the efforts, there is no readiness for BI processing. Identifying gaps in the readiness for BI can prevent waste of time and resources in places that lack the readiness may cause to the failure [30]. Second, readiness assessment indicates the necessary ways to fill these gaps and to successfully implement the BI [15] [30]. Experiences in this industry have shown that the approach beyond the traditional view is essential for determining the value of BI for organizations, and has been the subject of many types of research [15] [30]. BI implementation experiences show that the successful implementation of BI is beyond the implementation of the technical infrastructure (hardware aspects) and needs to control soft aspects and change management, which are known as the most difficult aspects of the successful implementation of BI applications. According to the studies, the soft aspects of BI implementation can be categorized in three dimensions of process, culture, and business management. Lake of processes and the lake of processes changes make the BI improvement ineffective, and no value would be achieved by investment. Hence, the process is about the basic aspects that its change readiness and appropriate change planning should be insured. Organizations that do continuous process improvement often have organizational improvement culture and are ready to technology and change acceptance. If an organizational culture resists to the change, it will also show greater resistance to BI adoption. Finally, resistance to change and new approaches adoption could be challenging in management levels, and without management 
International Journal of Information Technology Convergence and Services (IJITCS) Vol.6, No.1,February 2016

supports the change management and continues improvement would not be possible [30]. In the implementation readiness assessment, Williams and Williams reported that the organization's ability to achieve the ROI should be ensured. Moreover, they recommended that measures affecting the ROI should be identified and checked. These measures include both technical and business aspects [30]. The technical aspect refers to the process of creating a body of knowledge around data warehouse, which is the basis for acquiring, classifying and transferring BI information and applications. The business aspect refers to the criteria affecting the decisions on the profitability of BI applications. These readiness measures are a manageable business risk. Obtaining the wide range of privilege, from strong to weak, on the individual criteria of BI readiness is common for organizations. The strong privilege shows the organizations' capability that acts as the lever for success. Weak privilege reflects the risks that require the active management [30].

\subsection{Factors Affecting the BI Readiness}

The importance of readiness measurement leads to the development of some general readiness models. For example, the Gartner assessed the readiness in the five areas of operational, technical, project, cultural and awareness of resources and efforts. According to this model, the company is at one of the three levels of readiness, limited, or weak. The level of readiness has the highest success rate, but the limited level shows the low readiness and needs effort and change for readiness. The weak level that has the highest failure risk needs more effort and change for readiness to implement [12]. On the other side, researchers tried to provide the readiness model for IS such as the research have been done on the readiness for implementing enterprise resource planning (ERP) [19], customer relationship management (CRM) [22], and knowledge management (KM) [18]. Although less, but the willingness to BI implementation has been of interest to researchers. Based on the studies, four main models of organizational readiness assessment provided by Williams and Williams, Anjariny and Zeki, Anjariny et al., and Eckerson [29] [30] [1] [2] (see table.1).

Williams (2004) identified seven effective factors that two of them refer to the business factors, including strategic alignment and IT partnership, three factors refer to the culture, including the culture of continuous process improvement, the culture of engineering the decision-making process and the culture of using information and analysis, one factor refers to the use of a knowledge management approach including the functional use of BI, and one factor refers to the IT infrastructure including the BI technical readiness and data warehousing. Williams and Williams (2010) changed the functional use of BI to the portfolios. Moreover, Anjariny and Zeki [1] and Anjariny et al. [2] confirmed the Williams and Williams [29] model. Anjariny et al. have focused on explaining the clear strategy, strong commitment, partnership, measurement culture, and essential needs, availability and strong resources, available and reliable data, technical infrastructure, appropriate scale and scope and mid-level management support. While most of the factors are similar, factors such as the appropriate scale and scope and mid-level management support are new [2]. Anjarny et al. [2] introduced these factors as management, user, business, project, teamwork, infrastructure and data. They introduced three steps of extraction of effective factors, evaluation and questionnaire development, and create a model for organizational readiness assessment for achieving organizational readiness for implementing BI. But the question is whether the same factors affecting the organization's readiness or organizational differences require different readiness factors [2]. Hence, this study examines the organizational readiness for BI implementation in three organizations with the same infrastructure. The influential factors that have been shown to have an effect on the organizational readiness for BI implementation and their resources are listed in Table 2. 
Table 1. Prior studies on the organizational readiness for BI

\begin{tabular}{|c|c|c|}
\hline Resource & Objective & Main Findings \\
\hline [9] & $\begin{array}{l}\text { To show the characteristics of } \\
\text { successful BI solutions }\end{array}$ & $\begin{array}{l}\text { Characteristics of successful BI solutions are as follows: } \\
\text { - Business sponsors are strongly committed and involved in the project. } \\
\text { - Business users and BI technical teams work together. } \\
\text { - BI systems are seen as a corporation source, and appropriate funding } \\
\text { and instructions provide in order to ensure the long-term growth and } \\
\text { survival. } \\
\text {-Companies provide the static view and online interact for users. } \\
\text {-Data are } \\
\text { - BI team has previous experience of BI, and the vendor and the } \\
\text { independent consultants help them to set up partnerships. } \\
\text { The company's organizational culture reinforces the BI solutions. }\end{array}$ \\
\hline [29] & $\begin{array}{l}\text { To study the manufacturing } \\
\text { organizations to identify } \\
\text { barriers of readiness for BI }\end{array}$ & $\begin{array}{l}\text { The prevention of barriers to BI Readiness has been shown that include: } \\
\text { continuous process improvement, the culture of using information and } \\
\text { analysis. Moreover, the Culture of decision-making and business and IT } \\
\text { partnerships has been less than ideal, and government agencies on } \\
\text { factors such as strategic alignment, continuous process improvement, BI } \\
\text { technical readiness and DW had a problem. }\end{array}$ \\
\hline [1] & $\begin{array}{l}\text { To present a model for BI } \\
\text { readiness \& success }\end{array}$ & Ten readiness factors and six success factors have been introduced. \\
\hline [2] & $\begin{array}{l}\text { To review the history and } \\
\text { challenges of implementing BI } \\
\text { systems within the } \\
\text { organization. }\end{array}$ & $\begin{array}{l}\text { Provide an understanding of the strengths and weaknesses of readiness } \\
\text { for BI systems. Then a model has been developed for assessing the BI } \\
\text { Readiness. }\end{array}$ \\
\hline
\end{tabular}

Table 2. Studied factors based on the research objective

\begin{tabular}{|c|c|c|c|}
\hline & Factor & Description & Source \\
\hline \multirow{6}{*}{ Culture } & Loyalty & The action that people show in their relationships. & [8] [19] [27] \\
\hline & $\begin{array}{l}\text { Performance } \\
\text { measurement }\end{array}$ & $\begin{array}{l}\text { Organizations should have the culture of performance } \\
\text { measurement that is essential for assessing the organizational } \\
\text { readiness. }\end{array}$ & {$[1][9]$} \\
\hline & partnership & $\begin{array}{l}\text { The partnership should be in the organization's culture. Using } \\
\text { BI to create business value requires effective partnerships } \\
\text { between business and IT. }\end{array}$ & [29] \\
\hline & $\begin{array}{c}\text { Suitable } \\
\text { environment }\end{array}$ & $\begin{array}{l}\text { The suitable environment is necessary to make changes in the } \\
\text { organization. }\end{array}$ & [7] \\
\hline & $\begin{array}{l}\text { Culture of using } \\
\text { information }\end{array}$ & $\begin{array}{l}\text { Organizations that are accustomed to the use of information } \\
\text { and analytical frameworks do better in ROI of BI. }\end{array}$ & [29] \\
\hline & $\begin{array}{l}\text { The culture of } \\
\text { learning }\end{array}$ & One way of learning is freely speaking about the failures. & $([8][19][27]$ \\
\hline \multirow{4}{*}{ Individual } & $\begin{array}{l}\text { Individual's BI } \\
\text { skills }\end{array}$ & The skill that people gain by experience and education. & {$[4][10][22]$} \\
\hline & Knowledge & The knowledge that people gain by experience and education. & [1] \\
\hline & Commitment & People committed to change in organizations. & [2] [13] [14] [18] \\
\hline & Satisfaction & People must be willing to make a change in the organization. & {$[2]$} \\
\hline \multirow{3}{*}{ Management } & $\begin{array}{l}\text { Management } \\
\text { support }\end{array}$ & $\begin{array}{l}\text { When that leadership and management are involved in the } \\
\text { change process and BI implementation. }\end{array}$ & [1] [10] [27] [32] \\
\hline & innovation & $\begin{array}{l}\text { Innovation, adoption and implementation of new ideas, and } \\
\text { products and service processes }\end{array}$ & {$[25]$} \\
\hline & Resource allocation & $\begin{array}{l}\text { Management should provide the necessary resources for } \\
\text { change including financial and human resources. }\end{array}$ & [32] \\
\hline \multirow{3}{*}{ Strategy } & $\begin{array}{l}\text { Continuous process } \\
\text { improvement }\end{array}$ & $\begin{array}{l}\text { If the users do not create the required process changes for the } \\
\text { BI, the organizations' investment in BI will be wasted. }\end{array}$ & {$[30]$} \\
\hline & $\begin{array}{l}\text { Written business } \\
\text { plan }\end{array}$ & The organization should have a written business plan. & [7] \\
\hline & $\begin{array}{c}\text { Knowledge-based } \\
\text { decision-making }\end{array}$ & $\begin{array}{l}\text { If employees and managers know how to find and analyze } \\
\text { relevant data, decisions will be better. }\end{array}$ & [7] \\
\hline
\end{tabular}




\section{RESEARCH MODEL ANd HypothesizeS}

The objective of this study is to assess the organizational readiness for implementing BI. Therefore, based on the conceptual study and the research literature, a model based on the models of Anjariny et al. [2] and Anjariny and Zeki [1] has been developed. The model contains management, individual, culture and strategy as the factors affecting the readiness for BI implementation, which is shown in Figure 1, and associated hypotheses are explained as follows.

\section{- Culture}

The culture was introduced as the culture of measurement by Eckerson [9] and Anjariny et al. [2] and as the extent of cultural readiness by Gartner [12]. Then Anjariny and Zeki introduced the culture of measurement in their BI readiness model [1]. Williams and Williams introduced the culture of using information and analysis as the factor affecting the ROI of BI [29]. Therefore, the hypothesis 1 is explained as follows:

Hypothesis 1: culture is effective on the organization's readiness for BI implementation.

\section{- Individual}

Individual was introduced in the Anjariny and Zeki BI readiness model [1]. Strong teams and resources are considered as the effective factors of BI readiness [9]. Moreover, Anjariny et al. have determined the education, commitment, satisfaction, support and partnership as the factors affecting the readiness and success of BI [2]. Therefore, the hypothesis 2 is explained as follows: Hypothesis 2: the individual is effective on the organization's readiness for BI implementation.

\section{- Management}

Eckerson; Anjariny and Zeki, and Anjariny et al. have introduced mid-level managers' support and partnership as the effective factor on the BI readiness [9] [1] [2]. Moreover, Williams and Williams put the BI portfolio in the management category [29]. Therefore, the hypothesis 3 is explained as follows:

Hypothesis 3: management is effective on the organization's readiness for BI implementation.

\section{- Strategy}

Williams and Williams have introduced the strategic criteria as the strategic alignment [29], then Eckerson has clearly defined the strategy [9] and ultimately Anjariny and Zeki, used the Ackerson's definition in their BI readiness model [1]. Therefore, the hypothesis 4 is explained as follows:

Hypothesis 4: strategy is effective on the organization's readiness for BI implementation.

\section{Method: Participants And Data Collection}

The objective of this study is to assess organizational readiness for implementing BI. Hence, assuming the similar infrastructure of three studied organizations (i.e., educational, commerce and IT) and Based on the conceptual study, four factors of management, individual, strategy and culture and 18 indicators of innovation support, support of change, knowledge, commitment, loyalty, partnership, satisfaction, written business plan, suitable environment for changes, learning from failure, continuous process improvement, resources allocation, data warehouse and BI skills of individuals, use of information and analysis applications, performance measurement 
and knowledge-based decision-making, and their impact on the readiness of BI were examined. The extracted factors and their resources are shown in Table 4. The questionnaire was used for gathering the required data. The reliability and validity of the questionnaire were examined using experts' ideas and Cranach's alpha, which was 0.903 for the whole scale of the questionnaire. The participants of the study were 118 experts of the three organizations of commerce, IT, and education. According to the results, $42.74 \%$ of the respondents were men and $57.27 \%$ were women.

In terms of education, 9\% had a diploma, 49\% had an associate degree and 35\% had Master degree and $7 \%$ had a Ph.D. (the lowest). Moreover, 56\% of respondent were the employee and $5 \%$ were the lecturer; also $10 \%$ of them had worked experience for more than 10 years.

The partial least squares (PLS) method, a component-based structural equation modeling technique was used for analyzing the measurement and validity of the questionnaire and to analyze the model. This method simultaneously tests the strength of the relations between the hidden and observable variables [16].

\subsection{Data Analysis}

The factor loading coefficient, composite reliability, and the extracted average variance (AVE) were used to determine the adequacy of the measurement model. The AVE higher than 0.5, the composite reliability, higher than 0.7 and communality higher than 0.6 is acceptable [24], based on the results, the model is confirmed (see Table 3). Moreover, the hypotheses were tested by estimating the path coefficients and the R2 value. The bootstrap resampling method of PLS was used to determine the significance of the path coefficients. According to Chin [5], R2 higher than 0.67 is strong, higher than 0.33 is mediated and 0.19 is weak. Regarding the Table. 4 and R2 = 0.32, our model is at the mediated level. Moreover, according to Cirrone et al. [6] the model's goodness of fit (GOF) should be between 0.33 and 0.66 ; furthermore, the GOF higher than 0.35 as strong, 0.25 as mediated and 0.01 as weak [28]. Based on the result the GOF of the model is 0.51 and is strong.

Table.5 indicates the conformity factor analysis. According to the results, the loading of six factors (i.e., Suitable Environment, learning from failure, partnership, satisfaction, commitment, and Written Business plan) were less than 0.5 and were dropped from further analysis (see Table.4).

Table 3. Model Analysis

\begin{tabular}{|l|c|c|c|c|c|c|}
\hline & AVE & $\begin{array}{c}\text { Composite } \\
\text { Reliability }\end{array}$ & $\begin{array}{c}\mathbf{R} \\
\text { Square }\end{array}$ & $\begin{array}{c}\text { Cronbach's } \\
\text { Alpha }\end{array}$ & Communality & Source \\
\hline BI Readiness & 1 & $1 / 0$ & $0 / 32$ & $1 / 0$ & 1 & \\
\hline Culture & $0 / 85$ & $0 / 913$ & & $0 / 827$ & $0 / 85$ & {$[1][2][9][29]$} \\
\hline Individual & $0 / 80$ & $0 / 877$ & & $0 / 720$ & $0 / 80$ & {$[1][2][9]$} \\
\hline Management & $0 / 75$ & $0 / 846$ & & $0 / 641$ & $0 / 75$ & {$[2][2][9][29]$} \\
\hline Strategy & & & & & & \\
& $0 / 75$ & $0 / 847$ & & $0 / 700$ & $0 / 75$ & {$[1][9][29]$} \\
\hline
\end{tabular}


International Journal of Information Technology Convergence and Services (IJITCS) Vol.6, No.1,February 2016

The result of the structural model assessment is presented in Fig.1. Based on the results the fit of the overall model was acceptable. According to the Fig.2, the effects of culture (path coefficient = $-0.395, \mathrm{p}<0.05$ ) and management (path coefficient $=0.474, \mathrm{p}<0.05$ ) on the IT organization's readiness for BI implementation were confirmed. Thus, Hypotheses1 and 3 were accepted in IT organization. Based on the results, individuals had a positive effect on the educational (path coefficient $=0.229, \mathrm{p}<0.05$ ) and commerce (path coefficient $=0.472, \mathrm{p}<0.05$ ) organizations readiness for BI implementation. Thus, the Hypothesis 2 was supported in educational and commerce organizations. Furthermore, the results indicated that strategy (path coefficient $=$ $0.623, \mathrm{p}<0.01)$ has a positive effect on educational organization's readiness for $\mathrm{KM}$ implementation, therefore the Hypothesis 4 was supported in an educational organization. The results of hypothesis tests are presented in Table 5.

Table 4. Loading Factors

\begin{tabular}{|l|c|c|c|c|c|}
\hline & 1-Culture & 2-Individuals & 3-Management & 4- Strategy & BI Readiness \\
\hline $\begin{array}{l}\text { 1-1. Performance } \\
\text { Measurement }\end{array}$ & $\mathbf{0 . 8 6}$ & & & & \\
\hline 1-2. Loyalty Using & $\mathbf{0 . 9 6}$ & & & & \\
\hline $\begin{array}{l}\text { 1-3. Culture of anformation and Analytics } \\
\text { Informent }\end{array}$ & 0.36 & 0.314 & 0.31 & 0.63 & 0.01 \\
\hline 1-4. Suitable Environment & 0.27 & 0.30 & 0.18 & 0.62 & -0.01 \\
\hline 1-5. Learning from failure & 0.06 & 0.06 & 0.26 & 0.36 & 0.073 \\
\hline 1-6. Partnership & & $\mathbf{0 . 8 7}$ & & & \\
\hline 2-1. BI Skills & & $\mathbf{0 . 8 9}$ & & & \\
\hline 2-2. Knowledge & -0.20 & 0.42 & 0.21 & 0.30 & -0.11 \\
\hline 2-3. Satisfaction & 0.58 & -0.02 & 0.06 & 0.36 & -0.053 \\
\hline 2-4. Commitment & & & $\mathbf{0 . 8 8}$ & & \\
\hline 3-1. Management Support & & & & & \\
\hline 3-2. Innovation & & & & $\mathbf{0 . 8 2}$ & \\
\hline 4-1. Continuous Improvement & & & & & \\
\hline 4-2. Knowledge-Based \\
Decision-Making
\end{tabular}

Table 5. Tests of hypotheses

\begin{tabular}{|c|c|c|c|c|c|c|c|c|c|}
\hline \multirow[b]{2}{*}{$\begin{array}{c}\text { Hypothesi } \\
\text { s }\end{array}$} & \multicolumn{3}{|c|}{ Educational } & \multicolumn{3}{|c|}{ Commerce } & \multicolumn{3}{|c|}{ IT } \\
\hline & $\begin{array}{c}\text { Path } \\
\text { Coefficien } \\
t\end{array}$ & $\begin{array}{c}\mathbf{T} \\
\text { value }\end{array}$ & $\begin{array}{c}\mathbf{P} \\
\text { value }\end{array}$ & $\begin{array}{c}\text { Path } \\
\text { Coefficien } \\
t\end{array}$ & $\begin{array}{c}\mathbf{T} \\
\text { value }\end{array}$ & $P$ value & $\begin{array}{c}\text { Path } \\
\text { Coefficient }\end{array}$ & $\begin{array}{c}\mathbf{T} \\
\text { value }\end{array}$ & $\begin{array}{c}\mathbf{P} \\
\text { value }\end{array}$ \\
\hline H1 & $0.068^{\times}$ & $0.638^{\times}$ & $0.569^{\times}$ & $0.277^{\times}$ & $1.932^{\times}$ & $0.149^{\times}$ & $-0.395^{*}$ & $4.707 *$ & $0.018 *$ \\
\hline H2 & $0.229 *$ & $3.203 *$ & $0.05 *$ & $0.47^{*}$ & $5.607 *$ & $\begin{array}{c}0.0112 \\
*\end{array}$ & $0.228^{\times}$ & $1.487^{\times}$ & $0.233^{x}$ \\
\hline $\mathbf{H 3}$ & $-0.086^{\times}$ & $1.021^{\times}$ & $0.382^{\times}$ & $0.03^{\times}$ & $0.298^{\times}$ & $0.785^{\times}$ & $0.474 *$ & $5.503 *$ & $0.012 *$ \\
\hline H4 & $0.623^{* *}$ & $7.540 *$ & $0.005^{* *}$ & $-0.138^{\times}$ & $1.310^{\times}$ & $0.281^{\times}$ & $-0.095^{\times}$ & $0.613^{\times}$ & $0.583^{\times}$ \\
\hline Note1: $\begin{array}{r}\mathrm{P}<0 \\
\mathrm{P}<0\end{array}$ & Reje & & Note & $\geq 1.96^{*}$ & & & & & \\
\hline
\end{tabular}




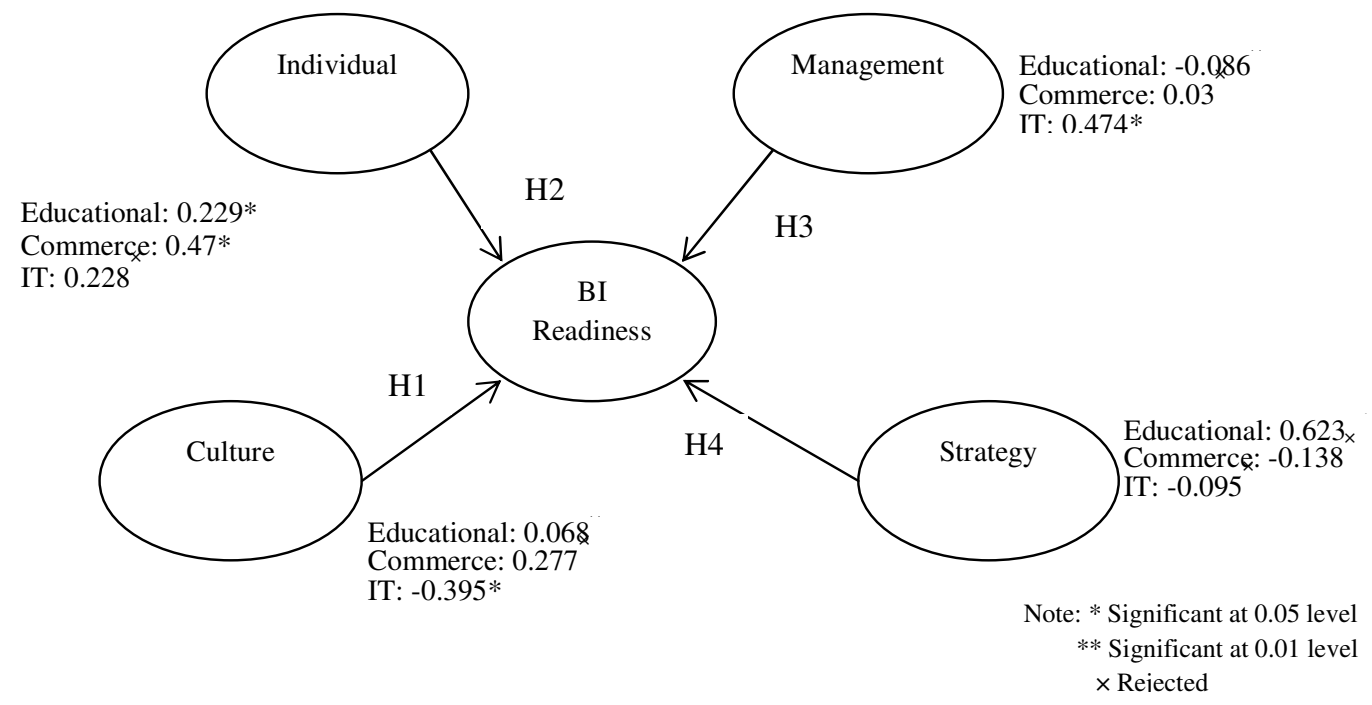

Fig 1. Result of Structural Model Test

\section{CONCLUSION AND RECOMMENDATIONS}

BI can help organizations to better understand their business. This study suggested some key points of achieving readiness to implement BI. The objective of the study is to examine the effects of culture and different IT assets on the factors affecting the BI implementation to understand whether the affective factors on the organizational readiness for implementation of the BI system in all organizations are identical or not. Hence, the factors affecting the BI readiness were extracted and were examined in three different organizations of IT, educational and commercial. The results of model assessment indicated the fit of the overall model. Based on the results, the strategy has a positive effect on the educational readiness for BI implementation. Moreover, consistent to the Anjariny et al. [2], and Anjariny and Zeki [1], the results confirmed the positive effect of the individual on the educational and commerce organizations' readiness for BI implementation. Furthermore, similar to the findings of Anjariny et al. [2], Anjariny and Zeki [1], and Eckerson [9] the effects of culture and management on the organizational readiness were confirmed in IT organization. But the culture had a negative effect on IT organization's readiness for BI implementation that could be due to the lack of suitable basis for involvement, and cooperation.

Based on the results, the different hypothesizes have been accepted in a different organization. Therefore, it can be concluded that there is no general model for all organizations, and based on the organization's scope and the number of the employees, different factors must be applied to prepare the organizations for BI implementation. Thus, it is suggested that organizations in which individuals are not closely related to IT should pay more attention to their personnel. Organizations should try to identify the factors affecting their readiness for BI implementation.

Despite the importance of $\mathrm{BI}$ and high statistics of its failure, there is limited research has on what factors affecting the organizational readiness for BI implementation. Moreover, limited research has been done in Iran. This study could help organizations that willing to implement BI. It is expected that the proposed model could increase the readiness of organizations to implement BI.

Finding the comprehensive model could help organizations willing to implement BI. The readiness for BI implementation is considered as the prerequisite for BI success in an organization; therefore, research in this area is essential. The next steps would be the sample 
collection, inventory, analysis and more comprehensive and broader modeling. Moreover, making the similar model to the Davenport maturity model in terms of readiness for BI implementation, and specifying the required measures to go to the next step could be a useful guide for managers. According to the results, organizations based on their scope should consider different factors. Therefore, it is better to investigate the research model in other areas.

\section{REFERENCES}

[1] Anjariny, Ahmed H., \& Akram M. Zeki.(2011). "Development of a model for assessing organizations' readiness toward successful Business Intelligence systems". In Research and Innovation in Information Systems (ICRIIS), 2011 International Conference on (pp. 1-6). IEEE.

[2] Anjariny, Ahmed H., Akram M. Zeki, \& Husnayati Hussin. (2012). "Assessing Organizations Readiness toward Business Intelligence Systems: A Proposed Hypothesized Model". In Advanced Computer Science Applications and Technologies (ACSAT), 2012 International Conference on (pp. 213-218). IEEE.

[3] Buchanan, Leigh, \& Andrew O Connell (2006). "A brief history of decision-making". Harvard Business Review, 84(1), p. 32.

[4] Cheng, Lei, \& Peng Cheng. (2011). "Integration: Knowledge management and business intelligence". In Business Intelligence and Financial Engineering (BIFE), 2011 Fourth International Conference on (pp. 307-310). IEEE.

[5] Chin, Wynne W. (1998). "The partial least squares approach to structural equation modeling". Modern methods for business research, 295(2), pp. 295-336.

[6] Cirrone, G. A. P., Donadio, S., Guatelli, S., Mantero, A., Mascialino, B., Parlati, S., \& Viarengo, P. (2004). "A goodness-of-fit statistical toolkit". Nuclear Science, IEEE Transactions on, 51(5), pp. 2056-2063.

[7] Davenport, Thomas H., Jeanne G. Harris, \& Robert Morison. (2010). Analytics at work: Smarter decisions, better results. Harvard Business Press.

[8] Davenport, Thomas H., \& Laurence Prusak (1998). Working knowledge: How organizations manage what they know. Harvard Business Press.

[9] Eckerson, Wayne. (2003). "Smart companies in the 21st century: The secrets of creating successful business intelligence solutions". TDWI Report Series, 7.

[10] Elbashir, Mohamed Z., Philip A. Collier, \& Steve G. Sutton. (2011). "The role of organizational absorptive capacity in the strategic use of business intelligence to support integrated management control systems". The Accounting Review, 86(1), pp. 155-184.

[11] El-Mekawy, Mohammed, \& Rusu, Lazar (2011). Organizational Culture Impact on Business-IT Alignment: A Case Study of a Multinational Organization. Paper presented at the 44th Hawaii International Conference on System Sciences (HICSS).

[12] Gärtner, Christian. (2013). "Enhancing readiness for change by enhancing mindfulness".Journal of Change Management, 13(1), pp. 52-68.

[13] Heisig, Peter. (2003). "Business process oriented knowledge management". In Knowledge management (pp. 15-44). Springer Berlin Heidelberg.

[14] Holt, D. T. (2000). "The measurement of readiness for change: A review of instruments and suggestions for future research". In the annual meeting of the academy of management, Toronto, Canada.

[15] Howson, Cindi. (2007). Successful business intelligence. Tata McGraw-Hill Education.

[16] Hulland, John. (1999). "Use of partial least squares_PLS_ in strategic management research: A review of four recent studies". Strategic Management Journal. 20 (2), pp.195-204.

[17] Isik, Oyku. (2009). "Business Intelligence Success: An Empirical Evaluation of the Role of BI Capabilities and Organization's Decision Environment". AMCIS 2009 Doctoral Consortium, p. 13.

[18] Jennex, Murray E., \& Lorne Olfman. (2005). "Assessing knowledge management success". International Journal of Knowledge Management, 1(2), pp. 33-49.

[19] Kwahk, Kee-Young, \& Jae-Nam Lee. (2008). "The role of readiness for change in ERP implementation: Theoretical bases and empirical validation". Information \& Management, 45(7), pp. 474-481. 
International Journal of Information Technology Convergence and Services (IJITCS) Vol.6, No.1,February 2016

[20] Leidner, Dorothy E. (2010). "Globalization, culture, and information: Towards global knowledge transparency". The Journal of Strategic Information Systems, 19(2), pp. 69-77.

[21] Malladi, Suresh. (2013). "Adoption of Business Intelligence \& Analytics in Organizations-An Empirical Study of Antecedents".

[22] Ocker, Rosalie J., \& Susan Mudambi. (2003). "Assessing the readiness of firms for CRM: a literature review and research model". In System Sciences, 2003. Proceedings of the 36th Annual Hawaii International Conference on (pp. 10). IEEE.

[23] Rasmussen, Nils H., Paul S. Goldy, \& Per O. Solli. (2002). Financial business intelligence: trends, technology, software selection, and implementation. John Wiley \& Sons.

[24] Seyed Abasszadeh, M., Amani, J., Khezri Azar, H., \& Pashouy, G. (2012). "An Introduction of Structural Equations Modeling by PLS Method and its Application in Behavioral Sciences". Oroumieh University Publication, pp. 126-139.

[25] Siemieniuch, C. E., \& Sinclair, M. A. (2004). "A framework for organizational readiness for knowledge management". International Journal of Operations \& Production Management, 24(1), pp.79-98.

[26] Turban, Efraim., Sharda, Ramesh, Jay E. Aronson, \& David King. (2008). Business intelligence: A managerial approach. Upper Saddle River: Pearson Prentice Hall.

[27] Weidong, Zhao, Dai Weihui, \& Yang Kunlong (2010). "The relationship of business intelligence and knowledge management". In Information Management and Engineering (ICIME), 2010 The 2nd IEEE International Conference on (pp. 26-29). IEEE.

[28] Wetzels, Martin, Gaby Odekerken-Schröder, \& Claudia Van Oppen. (2009). "Using PLS path modeling for assessing hierarchical construct models: Guidelines and empirical illustration". MIS quarterly, pp. 177-195.

[29] Williams, Steve, and Nancy Williams. (2004). "Assessing BI Readiness: A Key to BI ROI". Business Intelligence Journal, 9, pp. 15-23.

[30] Williams, Steve, and Nancy Williams. (2010). The profit impact of business intelligence. Morgan Kaufmann.

[31] Wixom Barbara H., Watson Hugh J., Reynolds Anne-Marie, \& Hoffer Jeffrey A. (2008). "Continental airlines continues to soar with business intelligence". Information Systems Management, 25(2), pp. 102-112.

[32] Zhao Zixuan, Navarrete Carlos, and Iriberri Alicia, (2012). "Open Source Alternatives for Business Intelligence: Critical Success Factors for Adoption". AMCIS 2012 Proceedings.P.29. 